\title{
HUBUNGAN DISMENORE DENGAN KINERJA AKADEMIK MAHASISWI ANGKATAN 2017 DAN 2018 DI STIKES MURNI TEGUH
}

\author{
Masta Melati Hutahaean \\ Program Studi D3 Kebidanan STIKes Murni Teguh \\ E-mail: mastahutahaean020101@gmail.com
}

\begin{abstract}
Many women experience menstrual disorders, including menstrual pain or often called dysmenorrhea. The prevalence of dysmenorrhea in young women is estimated to be between 20$90 \%$ and around $15 \%$ of adolescents reported severe dysmenorrhea. This severe dysmenorrhea causes them to be unable to carry out any activities and influence the academic performance of female students. This type of research is descriptive analytic with cross sectional design. The population in this study were all female students of 2017 and 2018 namely 135 female students. The sample amounted to 100 female students. Sampling is done using purposive sampling. Analyzed by univariate and bivariate with chi square test.The results of the bivariate test showed that there was a relationship between dysmenorrhea and the academic performance of Murni Teguh STIKes students ( $p$ value 0.01) with an OR of 4.38 which means that students who did not experience dysmenorrhea estimated their chances of 4.38 times having very satisfying academic performance compared to female students who experience dysmenorrhea. It is recommended that Murni Teguh STIKes be able to activate regular sports activities as a form of student activities for all female students, especially female students who experience dysmenorrhea, from simple physical movements and aerobic exercise that can reduce menstrual pain which can interfere with the student's learning activities.
\end{abstract}

Keywords: Dysmenorrhea, academic performance, female students

\begin{abstract}
Abstrak
Banyak wanita yang mengalami gangguan pada menstruasinya, diantaranya adalah nyeri haid atau sering disebut dismenore. Prevalensi kejadian dismenore pada remaja wanita diperkirakan antara 20-90\% dan sekitar 15\% remaja dilaporkan mengalami dismenore berat. Dismenore berat ini menyebabkan mereka tidak mampu untuk melakukan kegiatan apapun serta mempengaruhi kinerja akademik mahasiswi. Jenis penelitian ini adalah deskriptif analitik dengan desain cross sectional. Populasi dalam penelitian ini adalah seluruh mahasiswi angkatan 2017 dan 2018 yaitu sebanyak 135 orang mahasiswi. Sampel berjumlah 100 orang mahasiswi. Pengambilan sampel dilakukan dengan menggunakan purposive sampling. Dianalisa secara univariat dan bivariat dengan uji chi square. Dari hasil uji bivariat menunjukan bahwa ada hubungan antara dismenore dengan kinerja akademik mahasiswi STIKes Murni Teguh ( $p$ value 0,01) dengan OR sebesar 4,38 yang berarti bahwa mahasiswi yang tidak mengalami dismenore perkiraan peluangnya 4,38 kali memiliki kinerja akademik yang sangat memuaskan dibandingkan dengan mahasiswi yang mengalami dismenore. Disarankan agar STIKes Murni Teguh dapat mengaktifkan kegiatan olahraga rutin sebagai bentuk kegiatan kemahasiswaan bagi seluruh mahasiswi terutama mahasiswi yang mengalami dismenore mulai dari olahraga dengan gerakan fisik yang sederhana maupun olahraga aerobik yang dapat mengurangi nyeri haid yang dapat mengganggu aktifitas belajar mahasiswi.
\end{abstract}

Kata kunci : Dismenore, Kinerja Akademik, Mahasiswi 


\section{PENDAHULUAN}

Salah satu tanda wanita telah memasuki masa reproduksi adalah wanita mengalami menstruasi setiap bulan secara periodik. Peristiwa ini merupakan peristiwa alamiah dan lazim dialami oleh wanita sebagai tanda kesiapannya menjadi seorang ibu. Banyak wanita yang mengalami gangguan pada menstruasinya, diantaranya adalah nyeri haid atau yang sering disebut dismenorea (Hickey \& Balen, 2003 dalam Fajarini, 2018). Menurut Bobak, 2004; Amimi dan Suarna, 2014 dalam Ertiana, et.al 2016 menyatakan bahwa semua wanita mengalami menstruasi setiap bulannya. Ada beberapa gangguan yang dialami oleh wanita berhubungan dengan menstruasi yang dialaminya diantaranya adalah hipermenore, hipomenore, polimenore, oligomenore, amenore dan dismenore. Dismenore adalah nyeri perut yang dirasakan sebelum atau selama menstruasi yang mengganggu aktivitas wanita dan sering mengharuskan pasien untuk beristirahat dan meninggalkan aktivitas mereka selama berjamjam karena dismenore yang dialaminya.

Prevalensi kejadian dismenore pada remaja wanita diperkirakan antara $20-90 \%$ dan sekitar $15 \%$ remaja dilaporkan mengalami dismenore berat. Berdasarkan penelitian terdahulu diketahui bahwa di Amerika Serikat diperkirakan hampir $90 \%$ perempuan mengalami dismenore dan 10-15\% diantaranya mengalami dismenore berat yang menyebabkan mereka tidak mampu untuk melakukan kegiatan apapun (Handayani \& Rahayu, 2014). Angka kejadian disemenore di Indonesia diketahui sebesar $64,25 \%$ yang terdiri dari $54,89 \%$ dismenore primer dan 9,36\% dismenore sekunder.

Berdasarkan data Badan Pusat Staisti tahun 2018 menunjukkan bahwa jumlah penduduk Indonesia tahun 2017 yaitu sebesar 266.927.712 jiwa dan sekitar 66,3 juta atau 24,8\% diantaranya adalah remaja umur 10-24 tahun. Berdasarkan data dari National Health and Nutrition Examination Survey (NHANES), umur rata-rata menarche (menstruasi pertama) pada anak remaja di Indonesia yaitu 12,5 tahun dengan kisaran 914 tahun. Di Indonesia angka kejadian dismenorea tipe primer adalah sekitar 54,89\% sedangkan sisanya penderita dengan dismenore sekunder. Dismenore terjadi pada remaja dengan prevalensi berkisar antara $43 \%$ hingga $93 \%$, dimana sekitar $74-80 \%$ remaja mengalami dismenore ringan, sementara angka kejadian endometriosis pada remaja dengan nyeri panggul diperkirakan 25-38\%, sedangkan pada remaja yang tidak memberikan respon positif terhadap penanganan untuk nyeri haid, endometriosis ditemukan pada $67 \%$ kasus. Kelainan terjadi pada $60-70 \%$ wanita di Indonesia dengan $15 \%$ diantaranya mengeluh bahwa aktivitas mereka menjadi terbatas akibat dismenore (Suliawati, 2013 dalam Nurwana, et.al, 2017).

Hal yang sama juga terjadi terhadap aktivitas belajar yang rutinitas dilakukan oleh mahasiswi. Nyeri haid berlebihan hingga mahasiswi tidak dapat melakukan aktivitas yang dialami oleh mahasiswi di STIKes Murni Teguh Medan ini merupakan hal yang paling sering dialami oleh wanita pada masa remaja terutama pada remaja yang sering mengalami kecemasan dan kegelisahan yang dapat meningkatkan kadar prostaglandin dalam tubuh dan dapat meningkatkan rasa nyeri. Selain itu, dismenore yang terjadi pada mahasiswi bisa disebabkan oleh keadaan emosional seseorang, dimana mayoritas wanita saat mengalami hal ini secara emosional tidak stabil, apabila mereka tidak mendapatkan penjelasan yang baik tentang proses haid maka mudah timbul terjadinya dismenore. Ketidaksiapan remaja putri dalam menghadapi perkembangan dan pertumbuhan pada dirinya tersebut mengakibatkan gangguan psikis yang akhirnya menyebabkan gangguan fisiknya, misalnya gangguan haid seperti dismenore. Beberapa perempuan mengalami sakit atau kram di daerah perut bagian bawah saat haid berlangsung, bahkan ada yang sampai pingsan karena tidak tahan menahan rasa sakitnya Upaya untuk mengatasi dismenore diantara remaja membutuhkan penanganan yang terintegrasi dan menyeluruh, karena secara umum dapat mengganggu aktivitas sehari-hari dan dapat berdampak pada turunnya produktivitas kerja.

Berdasarkan survey awal yang dilakukan kepada 10 orang mahasiswi STIKes Murni Teguh diketahui bahwa terdapat 6 orang mahasiswi yang mengalami nyeri haid hingga tidak dapat melakukan aktivitas dengan keluhan nyeri yang berbeda-beda. Terdapat 2 orang mahasiswi yang menyatakan bahwa karena nyeri haid yang tidak tertahankan mereka tidak dapat mengikuti kegiatan 
perkuliahan di hari pertama dan kedua masa menstruasi, dan 4 orang mahasiswi lainnya menyatakan bahwa memilih untuk tetap masuk perkuliahan tetapi mereka kehilangan konsentrasi saat belajar hingga ada beberapa jam perkuliahan yang tidak diiukuti karena mereka memilih untuk beristirahat di klinik kampus. Mereka juga menyatakan bahwa seringkali menghadap dosen pengajar untuk meminta tugas karena ketidakhadiran mereka saat perkuliahan sehingga membuat mereka tidak dapat mendapatkan nilai saat pretest dan post test untuk mata kuliah tertentu. Rata-rata jam pembelajaran di STIKes Murni Teguh > 48 jam dalam satu minggu. Sedangkan 2 orang lainnya mengatakan mengalami beberapa remedial karena ujian yang tidak bisa dijawab karena ada beberapa materi inti dalam pokok bahasan perkuliahan yang tidak mereka ikuti dan ternyata materi tersebut dikeluarkan saat ujian. Diketahui pula terdapat peningkatan persentasi ketidakhadiran mahasiswi yang disebabkan karena sakit dan hampir setiap minggu terdapat mahasiswi yang meminta izin kepada wali kelas untuk tidak mengikuti perkuliahan baik yang pulang maupun beristirahat di klinik kampus.

\section{METODE PENELITIAN}

Penelitian merupakan penelitian deskriptif analitik dengan pendekatan cross sectional. Populasi target penelitian adalah seluruh mahasiswi angkatan 2017 dan 2018 yaitu sebanyak 135 orang mahasiswi. Sampel berjumlah 100 orang mahasiswi. Pengambilan sampel dilakukan dengan menggunakan purposive sampling.

$$
\text { Data dikumpulkan dengan }
$$
menggunakan kuesioner yang sebelumnya telah dilakukan uji validitas dan reliabilitas. Kuesioner secara garis besar berisi mengenai pertanyaan mengenai pengaruh nyeri terhadap kemampuan mereka melakukan kegiatan di kampus termasuk kinerja akademik yang diperolehnya. Analisis data menggunakan analisis univariat, bivariat dengan uji chisquare.

\section{HASIL PENELITIAN}

\section{Karakteristik Responden}

Mayoritas responden berusia 19 tahun (51\%) dengan rata-rata usia mahasiswi 20 tahun (Tabel 1).

\section{Dismenore}

Mayoritas responden tidak mengalami dismenore yaitu sebanyak 83 orang (83\%) (Tabel 1).

\section{Kinerja Akademik Mahasiswi}

Tabel 1.

Distribusi Frekuensi dan Persentase Karakteristik Responden, Dismenore dan Kinerja Akademik Mahasiswi STIKes Murni Teguh

\begin{tabular}{lcc}
\hline \multicolumn{1}{c}{ Variabel } & f & \% \\
\hline Umur & & \\
19 tahun & 51 & 51 \\
20 tahun & 41 & 41 \\
21 tahun & 8 & 8 \\
$(\bar{X}=20)$ & & \\
\hline $\begin{array}{l}\text { Dismenore } \\
\text { Tidak Dismenore }\end{array}$ & 83 & 83 \\
$\quad$ Dismenore & 17 & 17 \\
\hline $\begin{array}{l}\text { Kinerja Akademik } \\
\text { Mahasiswi }\end{array}$ & 78 & 78 \\
$\quad \begin{array}{l}\text { Sangat Memuaskan } \\
\text { Memuaskan }\end{array}$ & 22 & 22 \\
\hline $\begin{array}{l}\text { Dari hasil tabel 1 } \\
\text { mayoritas responden }\end{array}$ & memiliki kinerja \\
akademik yang sanga t memuaskan yaitu \\
sebanyak 78 orang (78\%).
\end{tabular}

\section{Hubungan Dismenore dengan Kinerja Akademik Mahasiswi}

Tabel 2.

Hubungan Dismenore dengan Kinerja Akademik Mahasiswi STIKes Murni Teguh

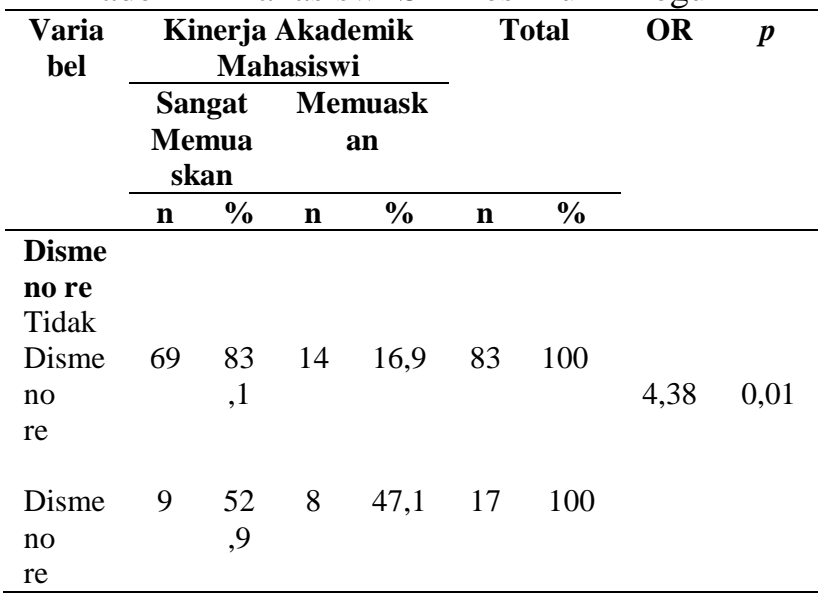

Hasil penelitian tentang hubungan dismenore dengan kinerja akademik mahasiswi menunjukan bahwa ada hubungan antara dismenore dengan kinerja akademik mahasiswi STIKes Murni Teguh ( $p$ value 0,01 ) dengan OR sebesar 4,38 yang berarti bahwa mahasiswi yang tidak mengalami dismenore perkiraan peluangnya 4,38 kali memiliki kinerja akademik yang sangat 
memuaskan dibandingkan dengan mahasiswi yang mengalami dismenore (Tabel 2).

\section{PEMBAHASAN}

Berdasarkan hasil penelitian ini diketahui bahwa ada hubungan dismenore dengan kinerja akademik mahasiswi di STIKes Murni Teguh ( $p$ value 0,01). Diketahui mayoritas mahasiswa yang tidak mengalami dismenore memiliki kinerja akademik yang sangat memuaskan yaitu ada sebanyak 69 orang $(83,1 \%)$.

Hasil penelitian ini sejalan dengan penelitian Derseh, et.al (2017) bahwa ada hubungan yang signifikan antara kejadian disemnore dengan kinerja akademik ( $p$ value $<0,001)$. Sejalan pula dengan penelitian Fajarini (2018) mengenai prestasi belajar pada remaja yang mengalami dismenore primer yang menunjukan bahwa terdapat hubungan antara dismenore primer dengan prestasi belajar.

Namun hasil penelitian ini berbeda dengan penelitian Sumartini (2014) yang menunjukan tidak ada hubungan antara dismenore dengan prestasi belajar mahasiswi. Perbedaan yang diperoleh bisa dari pola gaya hidup responden yang diteliti atau perbedaan dalam persepsi nyeri selama menstruasi.

Banyak perubahan khas yang terjadi secara biologis baik pada remaja laki-laki maupun remaja perempuan. Salah satu tanda keremajaan yang muncul secara biologis pada perempuan yaitu remaja ini akan mengalami menstruasi. Menstruasi biasanya dimulai antar usia 10 dan 16 tahun dan akan berakhir pada masa menopause yaitu 45-50 tahun. Menstruasi sendiri adalah masa perdarahan yang terjadi pada perempuan secara rutin setiap bulan selama masa suburnya kecuali apabila terjadi kehamilan (Saguni, 2013). Wanita yang mengalami menstruasi kerap kali mengalami nyeri haid yang berlebih hingga mengganggu aktifitas sehari-harinya.

Dismenore adalah keluhan yang sering dialami perempuan pada bagian perut bawah. Secara etimologi, dysmenorrhea berasal dari kata dalam bahasa Yunani kuno. Kata tersebut berasal dari $d y s$ yang berarti sulit, nyeri, abnormal; meno yang berarti bulan; dan rrhea yang berarti aliran. Dengan demikian, secara singkat dysmenorrhea dapat disefinisikan sebagai aliran menstruasi yang sulit atau menstruasi yang mengalami nyeri.
Banyak hal yang berpengaruh terhadap prestasi belajar mahasiswa. Salah satunya adalah kesehatan. Berdasarkan Slameto (2010) belajar merupakan proses usaha yang dilakukan seseorang untuk memperoleh suatu perubahan tingkah laku yang baru secara keseluruhan, sebagai hasil pengalamannya sendiri dalam interaksi dengan lingkungannya. Kegiatan belajar dikatakan berhasil bila diperoleh hasil yang optimal sehingga perlu adanya penilaian atau evaluasi untuk mengetahui sejauh mana prestasi belajar yang telah diperoleh.

Nyeri merupakan suatu kondisi yang lebih dari sekedar sensasi tunggal yang disebabkan oleh stimulus tertentu. Nyeri bersifat subjektif dan sangat bersifat individual. Stimulus nyeri dapat berupa stimulus yang bersifat fisik dan mental. Gejala-gejala tersebut adalah alasan utama mahasiswi sulit konsentrasi selama berada di kelas, ketidakhadiran, kurangnya berpartisipasi dalam kegiatan kampus serta kurang forkus pada waktu ujian dan ketidakmampuan untuk menjawab dengan benar saat ujian. Berdasarkan temuan diketahui bahwa menstruasi dengan disemenore merupakan masalah kesehatan yang penting pada mahasiswi yang memiliki efek negatif pada kinerja akademik mereka.

Prestasi belajar mahasiswa STIKes Murni Teguh dapat dilihat melalui mutu akademiknya yang akhirnya dapat dilihat dari perolehan indeks prestasi yang merupakan nilai kredit rata-rata yang merupakan satuan akhir yang menggambarkan mutu penyelesaian suatu program setiap semesternya.

Meskipun demikian banyak hal yang mempengaruhi pencapaian hasil belajar seseorang selain daripada kesehatan seperti lingkungan kampus, kualitas dosen, metode pengajaran yang disampaikan oleh dosen, kelengkapan sarana dan prasarana, kondisi serta kenyamanan ruang belajar, jumlah mahasiswa yang ada di kelas. Hal tersebut turut serta mempengaruhi keberhasilan belajar seorang mahasiswi. Selain faktor eksternal tersebut terdapat faktor dari dalam diri mahasiswa yang berpengaruh terhadap pencapaian kinerja akademik seperti tingkat stres dan intelegensia seorang mahasiswi. 


\section{KESIMPULAN}

Dapat disimpulkan bahwa dismenore terbukti berhubungan dengan kinerja akademik mahasiswi STIKes Murni Teguh Medan.

\section{SARAN}

Disarankan agar STIKes Murni Teguh dapat mengaktifkan kegiatan olahraga rutin sebagai bentuk kegiatan kemahasiswaan bagi seluruh mahasiswi terutama mahasiswi yang mengalami dismenore mulai dari olahraga dengan gerakan fisik yang sederhana maupun olahraga erobik yang dapat mengurangi nyeri haid yang dapat mengganggu aktifitas seharihari mahasiswi terutama kegiatan belajar.Olahraga secara rutin dapat meningkatkan produksi endorphin otak yang dapat menurunkan stres sehingga secara tidak langsung dapat mengurangi nyeri saat menstruasi. Selain itu pula diperlukan dukungan psikologis dan akademik kepada mahasiswi yang mengalami penurunan kinerja akademik akibat dari dismenore yang dialaminya.

Kepada mahasiswi khususnya yang mengalami disemenore diharapkan dapat mengubah gaya hidup terutama latihan fisik secara teratur dan mengkonsumsi makanan yang dapat meningkatkan status gizi mahasiswi.

\section{REFERENSI}

Derseh, B.T., Afessa,N., Temesgen, M., Semayat, Y.W., Kassaye.M., Sieru, S., Gizachew, S., Ketsela. K. (2017). Prevalence of Dysmenorrhea and its Effects on School Performance: A Cross-Sectional Study. Journal of Women's Health Care 6(2). Diakses tanggal 17 Desember 2019 dari file:///C:/Users/Lenovo/Downloads/pr evalence-of-dysmenorrhea-and-itseffects-on-school-performance-acrosssectional-study-2167-04201000361.pdf

Ertiana, D., Akhyar, M., Budihastuti, U.R. (2016) Path Analysis of Factors which Correlated with Dysmenorrhea. Journal of Medicine 1(2):136-145. Diakses tanggal 29 Januari 2019: file:///C:/Users/Lenovo/Downloads/23 5346-path-analysis-of-factors-whichcorrelate-26e6e716.pdf
Fajarini, Y.I., Nurdiati, D.S., Padmawati, R.S. (2018). Prestasi Belajar pada Remaja yang Mengalami Dismenorea Primer. Jurnal Kesehatan Reproduksi 5 (1) $: 24-31$.

Handayani, E.Y., Rahayu, L.S. (2014). FaktorFaktor yang berhubungan dengan Nyeri Menstruasi (Dismenorea) pada Remaja Putri di Beberapa SMA di Kabupaten Rokan Hulu. Jurnal Maternity and Neonatal 1 (4): 161 171. Diakses tanggal 24 Januari 2019 dari:

file:///C:/Users/Lenovo/Downloads/11 07-2783-1-PB.pdf

Saguni, F. C. A., Madianung, A., Masi, G. (2013). Hubungan Dismenore dengan Aktivitas Belajar Remaja Putri di SMA Kristen I Tomohon. E-Journal Keperawatan $(e-K p) 1$ (1). Diakses tanggal 16 Januari 2019 dari https://ejournal.unsrat.ac.id/index.php/ $\mathrm{jkp} /$ article/view/2182/1740

Slameto. (2010). Belajar dan Faktor-Faktor yang Mempengaruhi. Jakarta: Rineka Cipta.

Sumartini. (2014). Hubungan Dysmenorhea dengan Prestasi Belajar Mahasiswi Jurusan Keperawatan Angkatan 2011 Fakultas Ilmu Kesehatan UIN Alauddin Makassar. Skripsi. UIN Alauddin Makasar. 